\title{
Digging deeper
}

\section{Arsenic contamination of groundwater affects millions of people in southern Asia. Water from deep wells could help, but only if used in moderation.}

The surface waters of southern Asia carry water-borne diseases such as diarrhoea, dysentery and typhoid, and, until relatively recently, were the main source of drinking water in this part of the world. As a result, bacterial infection and infant mortality was rife. In an effort to curb disease, millions of shallow tubewells - which tap into the shallow, pathogen free aquifer - have been constructed over the past few decades. The use of these wells has helped to control bacterial infection, but has also exposed millions of people to a potentially lethal toxin - arsenic.

Arsenic occurs naturally in sediments all over Asia, and is a particular problem in areas dominated by Holocene and organic-rich sediments (Nature Geosci. 1, $536-542 ; 2008$ ). Yet a study on page 46 of this issue shows that human alteration of the landscape, specifically the construction of artificial ponds, is making matters worse, as these ponds contain significant quantities of easily degradable organic carbon - a known factor in arsenic mobilization. Groundwater pumping draws pond water to depth, causing arsenic to be released from sediments into groundwater, and thus into the human food chain. Ironically, the ponds are excavated to protect villagers from contaminated water.

In regions where surface water is plagued with pathogens and the shallow aquifer is contaminated with arsenic, options for obtaining safe drinking water are scarce, but sorely needed. Ingestion of the poison over sustained periods of time can cause various forms of cancer, neurological damage, cardiovascular and pulmonary disease. Filtration of well water to remove the arsenic is one option. But, as noted in a Commentary on page 2 of this issue, filters are expensive by poor people's standards, and cumbersome to maintain, especially for someone already weakened by arsenic poisoning. What's more, regular filter testing to ensure timely replacement of failing devices is not feasible in countries such as Bangladesh.

From today's point of view, the most promising possibility seems to be the extraction of water from the arsenic-free deep aquifer, which could offer an effective and speedy solution. However, given the history of unforeseen consequences associated with the search for safe drinking water in this area of the world, caution is needed. According to model simulations, the removal of large volumes of pristine water from depth could simply draw arsenic-bearing waters from the shallow aquifer into the deep aquifer, thereby increasing the volume of contaminated water (Nature Geosci. 2, 383-384; 2009). But, if uncontaminated water from the deep aquifer is exploited with moderation - for example, if it is used to meet domestic but not irrigation needs, it could prove to be a precious resource.

Of course, that still leaves the question of what to do with the rice paddies. Dryseason rice production in Bangladesh relies heavily on irrigation with arseniccontaminated water, and the addition of large quantities of arsenic to arable soils each year could potentially reduce both rice quality and quantity. But this problem may be manageable, at least where monsoon rains are ample and regular. On page 53 of this issue, Roberts et al. show that monsoon flooding washes away a large portion of the arsenic that accumulates in rice-paddy soils owing to irrigation with contaminated water.

Using water from the shallow aquifer for irrigation, and the deep aquifer for the extraction of drinking water, could potentially help mitigate one of the worst public health concerns in southern Asia.

\section{Big brother meets climate change}

\section{Self-censorship of private scientific e-mail-exchanges cannot be the solution to the threat from hackers.}

It would be easy for climate scientists to become paranoid following the public exposition of thousands of private messages in one climate researcher's inbox. The illegal hack into the computers of the world-renowned Climatic Research Unit in Norwich, UK has brought the dwindling fringe of climate change deniers a rare flurry of media attention.

Whatever is written in the e-mail exchanges of any one climate researcher will not make a noticeable dent in the scientific case for global warming. Both the community of researchers and the independent lines of evidence are too diverse to allow this to happen.
Nevertheless, the story - big brother meets climate change - was too good to let go, and the timing, just before the Copenhagen climate conference, was perfect.

Amidst the calls for more caution in communication, it must be remembered that e-mails are an essential scientific tool when research groups span continents and schedules are tight. Yes, there is a limit to what should be put in writing. But in messages that are not meant for the public eye, there must be room for an openminded and opinionated discussion, for example, of the quality of papers published by other authors. And when writing to someone who is familiar with the context, there is generally no need to choose every word quite so carefully.

If private messages are exposed through criminal activities, it is important for the affected parties to make the context available to the public speedily. And in the case of the Norwich e-mails, more climate researchers should have assured the public more quickly that the case for human-induced climate change is not affected. The alternative - making every private e-mail between scientists unambiguous and fit for public consumption — would seriously hinder the progress of science. 